\title{
Melanin-containing feedstuffs protect Litopenaeus vannamei from white spot syndrome virus
}

\author{
Nguyen Dinh Thang $\cdot$ Le Dinh Tu $\cdot$ Nguyen Thi Le Na $\cdot$ Ngo Thi Trang $\cdot$ \\ Phan Tuan Nghia
}

Received: 8 April 2019/Accepted: 26 August 2019/Published online: 5 September 2019

(C) The Author(s) 2019

\begin{abstract}
Viral diseases are a serious issue for the shrimp aquaculture industry. White spot syndrome virus (WSSV) has been considered one of the most dangerous pathogens infecting cultured shrimp, causing a mortality rate as high as $100 \%$ within $7-10$ days of viral infection. So far, several protocols have been applied to protect shrimp against virus attacks, but their protection efficiency is very limited. In this study, for the first time, three melanin-containing feedstuffs (F1, F2, and F3) were formulated and fed to cultured shrimp to investigate the ability of melanin to protect shrimp from WSSV. The obtained results showed that F2 had a protection rate of $64 \%$ at day 7 and $62 \%$ at day 10 after virus challenge. The protection ability of the feedstuff depended on the amount of melanin consumed by shrimp. Moreover, our results also demonstrated that the transcription level of the VP28 gene, which codes for the VP28 protein, a representative for the presence of WSSV, was significantly decreased in shrimp fed F2. Taken together, our study suggests that melanincontaining diets may be applied in aquaculture to protect shrimp against WSSV infection; further, combined protocols with the simultaneous use of melanin-containing diets and other protectants should be studied and applied to increase the protection efficiency.
\end{abstract}

Keywords Litopenaeus vannamei - White spot syndrome virus (WSSV) - VP28 - Protection rate · Melanincontaining feed stuff

\section{Introduction}

Litopenaeus vannamei is mainly cultured in South African and Asian countries, especially Brazil, Ecuador, Mexico, China, Thailand, Indonesia, and Vietnam (Weidner and Rosenberry 1992; Jiravanichpaisal et al. 2001; Guzman et al. 2009; Gunalan et al. 2014). Approximately 3.7 million tons of Litopenaeus vannamei were produced in 2014. Shrimp export is considered a major sector providing considerable economic benefits to these countries. However, shrimp aquaculture continues to face the serious problem of infectious diseases caused by fungi, bacteria, and especially viruses. So far, more than 20 types of viruses have been reported as shrimp pathogens. Among these, white spot syndrome virus (WSSV) has been considered one of the worst

N. D. Thang $(\bowtie) \cdot$ L. D. Tu $\cdot$ N. T. Le Na $\cdot$ N. T. Trang $\cdot$ P. T. Nghia

Department of Biochemistry and Molecular Biology, Faculty of Biology, VNU University of Science, Vietnam National University, 334 Nguyen Trai St., Thanh Xuan Dist., Hanoi, Vietnam

e-mail: ndthang@hus.edu.vn

N. D. Thang · P. T. Nghia

Key Laboratory of Enzyme and Protein Technology, VNU University of Science, Vietnam National University, 334 Nguyen Trai St., Thanh Xuan Dist., Hanoi, Vietnam 
pathogens because of its strong dissemination and infectious abilities. More seriously, WSSV can lead to a 100\% mortality rate among cultured shrimp within 3-10 days after infection (Jiravanichpaisal et al. 2001; Jiravanichpaisal et al. 2006a, b; Guzman et al. 2009).

VP28 $(28 \mathrm{kDa})$ is an important structural protein of WSSV that can be used as a marker to determine the presence of WSSV in water or/and shrimp samples (Hoffmann et al. 1999; Lin et al. 2002; Tang et al. 2007; Nguyen et al. 2014). Shrimp immunity heavily relies on the innate immune system rather than andaptive immune system (Hoffmann et al. 1999; Nguyen et al. 2014). The innate immunity of shrimp includes cellular barriers and humoral barriers. These barriers play critical roles to protect shrimp from attacks of pathogens via mediating phagocytosis and initiating the apoptosis pathway (Van de Braak et al. 2002; Jiravanichpaisal et al. 2006a, b; Balasubramanian et al. 2008; Liu et al. 2009; Tassanakajon et al. 2010). In addition, melanization is also an important immune mechanism in shrimp (Jiravanichpaisal et al. 2001).

Many studies have been conducted to find solutions that protect shrimp from viral attacks; however, no real effective protocol has been reported. So far, several products including plant extracts and protein-/DNA-based vaccines have been developed, but these protectants have many limitations such as low protection efficiencies (Balasubramanian et al. 2006; Pholdaeng and Pongsamart 2010; Sudheer et al. 2011; Vaseeharan et al. 2006) and problems related to genetically modified organisms and genetically modified feeds (GMO/GMF) (Witteveldt et al. 2004; Rout et al. 2007; Sutthangkul et al. 2017).

Melanin is a natural polymer with very low toxicity (Garcia Borron et al. 2014). Melanin has many important roles in the human body including UV-radiation absorbent (Brenner and Hearing 2008), antioxidant (Vate and Benjakul 2013), and heavy-metal absorbent properties (Cuong et al. 2018). Melanization and melanin secretion help shrimp protect themselves by encapsulating pathogens and excreting them into the environment (Charoensapsri et al. 2014; Sutthangkul et al. 2015; Harikrishnan et al. 2011). However, no studies have examined the role of melanin as a supplement in protecting shrimp from pathogen attacks. Therefore, in this study, for the first time, we created melanin-containing feedstuffs and applied them to cultured Litopenaeus vannamei to investigate their abilities to protect shrimp against WSSV.

\section{Materials and methods}

Laboratory-scale shrimp culture

An experimental model for shrimp culture was set up based on a previous report (Nguyen et al. 2014). The designed culturing pool had a size of $45 \times 25 \times 30 \mathrm{~cm}$ with air-supplier and water filtration-circulation pump systems. Each pool was filled with $15 \mathrm{~L}$ of artificial seawater adjusted to $16 \%$ salinity, and seeded with 25 shrimp. The filter was washed every day and the cultured water was replaced with $70 \%$ freshwater every 3 days. The culturing temperature was maintained at $24-28{ }^{\circ} \mathrm{C}$. Feedstuffs were supplied four times per day, at $10 \mathrm{~g}$ each feeding.

Determination of dose of WSSV for $75 \%$ shrimp death $\left(\mathrm{LD}_{75}\right)$

WSSV was isolated from WSSV-infected shrimp in a previous study (Nguyen et al. 2014). After replacing with freshwater, WSSV solutions with viral doses of $1 \times 10^{4}, 5 \times 10^{4}, 1 \times 10^{5}, 5 \times 10^{5}$, and $1 \times 10^{6}$ copies $/ \mathrm{mL}$ were added to culturing pools, and shrimp were challenged with WSSV for 3 days. During virus challenge, water filtration-circulation pumps were stopped to avoid virus loss. After challenge, culturing systems were activated as usual and cultured for next 7 days. Every day, dead shrimp were collected and counted for mortality rate calculation to determine the $\mathrm{LD}_{75}$ value.

Preparation of melanin-containing feedstuffs

Melanin was extracted from Splendid Squid (Loligo formosana) as reported in our previous study (Cuong et al. 2018). Commercial feed in the bead form with a diameter of $2 \mathrm{~mm}$ (containing 45-50\% starch) was used as the core feed to produce melanin-containing feedstuffs with different formulas. Formula $1(F 1)$ : melanin was coated on the surface of the commercial beads using cod oil as a binding agent. At first, melanin powder 
$(<150 \mu \mathrm{m}$ in size) was distributed into cod oil and evenly coated on the commercial feed beads at different ratios (w/w) of 1/500,1/200, and 1/50. Formula $2(F 2)$ : melanin powder was well mixed with commercial powder, and starch solution $(3 \%)$ was used as cohesive agent. First, commercial feed beads were ground into a powder and sieved through a $150-\mu \mathrm{m}$ pore. Then commercial feed powder and melanin powder were well mixed at different ratios of 1/500, 1/200, and 1/50 (w/w) and evenly distributed in $3 \%$ starch solution. Next, the mixtures were pushed through a tube to form beads with a diameter of $2 \mathrm{~mm}$. Formula 3 (F3): commercial feed beads were directly dipped into squid ink-sac liquid at a 1/1 (w/v) ratio. All feedstuffs were dried at room temperature $\left(25^{\circ} \mathrm{C}\right.$ ) and kept in a $4{ }^{\circ} \mathrm{C}$ incubator before use. Commercial feedstuff (NURTRA-BEST, No. 880) for shrimp was purchased from Tongwei Vietnam Ltd. The ingredients of the feedstuff were recorded as follows: humid max. of $11.0 \%$, total protein min. of $40.0 \%$, digestible protein min. of $37 \%$, energy (Kcal $/ \mathrm{kg})$ of 3200 , total lipid min. of $5.0 \%$, total fiber max. of $3.0 \%$, calcium content max. of $2.3 \%$, total phosphor content of $1.25-2.5 \%$, lysine content of $1.8 \%$, and methionine content of $0.6 \%$.

Experimental design to investigate the ability of melanin-containing feedstuffs to protect shrimp against WSSV attack

Shrimp were divided into five groups: Group 1 (negative control group) shrimp were supplied with commercial feed without virus challenge; Group 2 (positive control group) shrimp were supplied with commercial feedstuff and challenged with virus $\left(1 \times 10^{6}\right.$ copies/mL); Groups 3, 4, and 5 (experimental groups) shrimps were supplied with feedstuff formula 1,2 , or 3 , respectively, and challenged with virus $\left(1 \times 10^{6} \mathrm{copies} / \mathrm{mL}\right)$. All the experiments were repeated three times. After challenge, shrimp were continuously cultured for 7 days and dead shrimp were collected and counted for mortality rate calculation to determine the protection rates (PRs) of the various feedstuff formulations. The PR was calculated based on the following formula:

$$
\mathrm{PR}(\%)=1-\frac{\text { mortality rate of experimental group }}{\text { mortality rate of positive group }} \times 100 \text {. }
$$

Real-time-PCR analysis

Total RNA was isolated from mouse tissue using the GeneJET RNA Purification (Thermo Scientific, Singapore), according to the manufacturer's instructions. Then cDNA was synthesized from total RNA by reverse transcriptase reaction, according to the protocol supplied with the RevertAid First Strand cDNA Synthesis Kit (Thermo Scientific, Singapore). Real-time quantitative RT-PCR was performed in a LightCycler ${ }^{\circledR} 96$ Instrument (Roche Diagnostics GmbH, Mannheim, Germany). Expression levels of VP28 were measured by quantitative RT-PCR, and adjusted through the transcript expression level of $\beta$-actin (an internal control). The primer sequences of VP28 and $\beta$-actin were presented as below:

VP28-Forward: 5'-CCCAAGCTTGATCTTTCTTTCACTCTTTCGG-' 3 ; and VP28-Reverse: 5'-AAAGAA TTCTTACTCGGTCTCAGTGCCAGAG-'3, (615 bp) (Nguyen et al. 2014).

$\beta$-Actin-Forward: 5'-TGTGTGACGACGAAGTAGCC-3; and $\beta$-actin-Reverse: 5'-TGGTCGTGAAGG TGTAACCA-'3 (605 bp) (Wang et al. 2007).

PCR products were used for electrophoresis running on agarose gel.

\section{Results}

High WSSV dose results in the death of $75 \%$ of shrimp $\left(\mathrm{LD}_{75}\right)$

The obtained results showed that shrimp began to die on day 3 after challenging with virus at concentrations of $5 \times 10^{5}$ and $1 \times 10^{6}$ copies $/ \mathrm{mL}$, and the mortality increased rapidly over the next 5 days. Particularly, at day 7 , the cumulative number of dead shrimp in the pools challenged with $5 \times 10^{5}$ and $10^{6}$ copies $/ \mathrm{mL}$ virus were $30 \%$ and $80 \%$, respectively; but, no shrimp had died by day 7 in the pools challenged with low viral concentrations $\left(1 \times 10^{4}, 5 \times 10^{4}\right.$, and $1 \times 10^{5}$ copies $\left./ \mathrm{mL}\right)$. Based on this result, the $\mathrm{LD}_{75}$ of WSSV for shrimp was determined to be $10^{6}$ copies/mL for a 7 -day challenge (Fig. 1a). The results also indicated that 


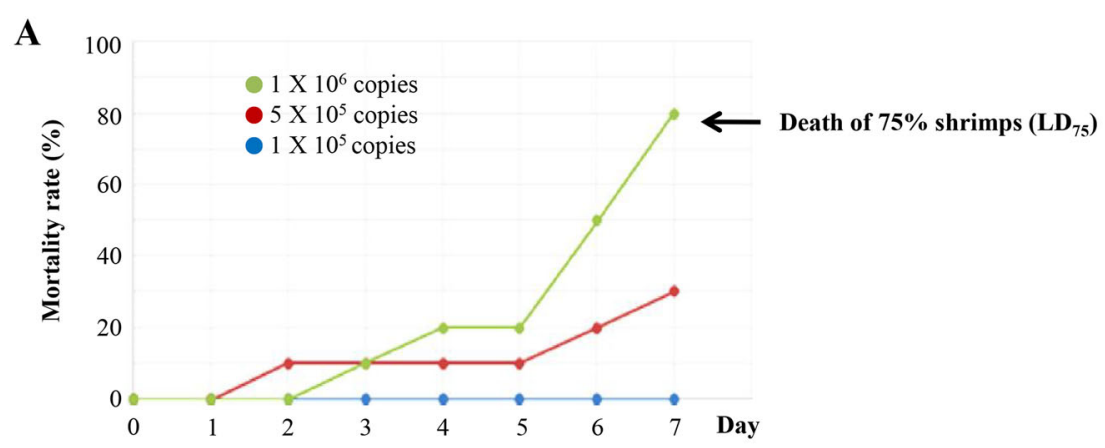

B

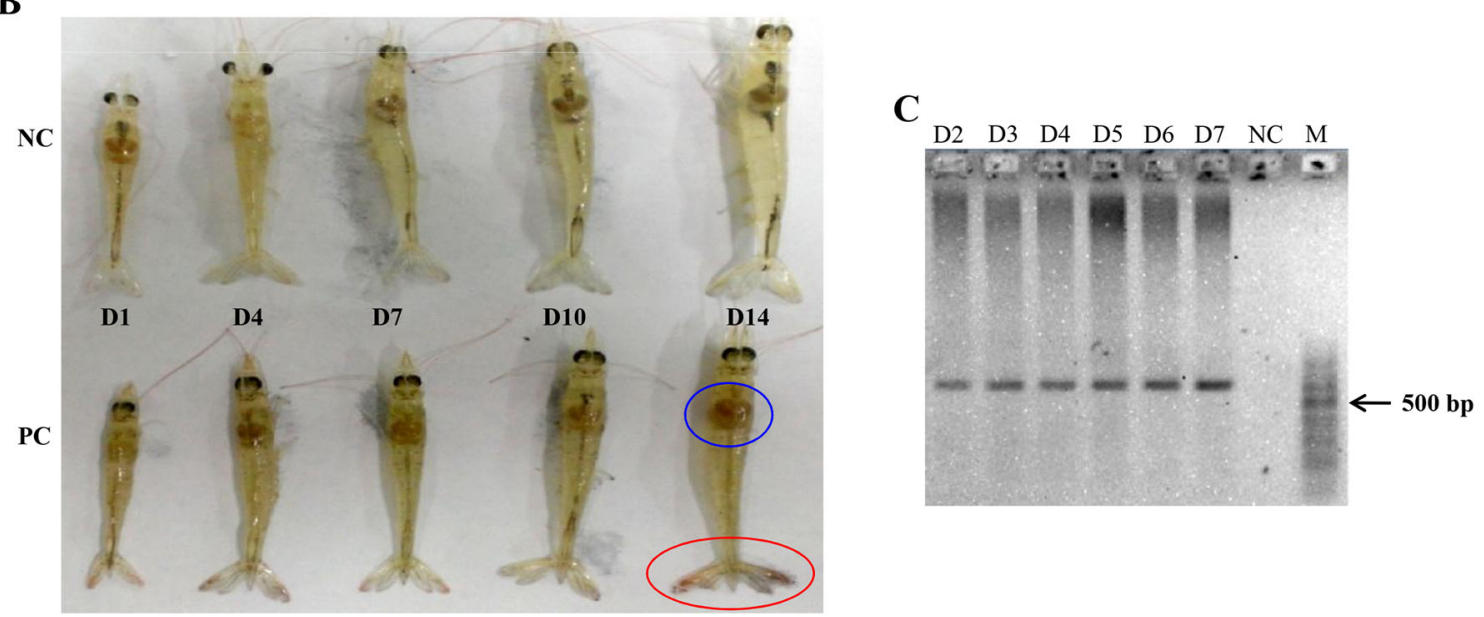

Fig. 1 Lethal dose of WSSV for 70\% (75\%) shrimp death. a Mortality rates of shrimps challenged with various WSSV concentrations; b morphologies of negative control (NC) shrimps and WSSV-infected shrimps (positive control-PC) at day 1 (D1), day 4 (D4), day 7 (D7), day 10 (D10), and day 14 (D14) post-viral infection; c transcript expressions of VP28 gene in PC and NC shrimps at day 2 (D2), day 3 (D3), day 4 (D4), day 5 (D5), day 6 (D6) and day 7 (D7) post-WSSV infection. The blue and the red circle signals indicated the necrotic head and red tail occured on the WSSV-infected shrimps, respectively

shrimp in the WSSV-challenged pool had typical signs of viral infection such as red tails and necrotic heads, while shrimp in the control pool did not have these signs (Fig. 1b). Further, the PCR results confirmed the presence of virus in the WSSV-infected shrimp via VP28 expression (Fig. 1c).

Melanin-containing feedstuffs protect shrimp from WSSV infection

Three melanin-containing feedstuffs named F1, F2, and F3 were produced and are presented in Fig. 2a. Although F1, F2, and F3 feedstuffs were initially made with different melanin/feed ratios, including 1/500, $1 / 200$, and $1 / 50$, our preliminary results indicated that the $1 / 200$ ratio was the most suitable one (data not shown) and thus we used the feedstuff with this ratio for further experiments. Shrimp were cultured and fed with F1, F2, or F3 feedstuffs, then challenged with WSSV for 3 days. The dead shrimp were collected and counted. The results showed that while the mortality rate of shrimp in the negative control pool was always stable at a low level (around 2-4\%), that of the positive control pool was very high: generally, in the positive pool, shrimp started to die at day 3, the death rate quickly increased over the next 5 days, and the mortality rate reached about $70-80 \%$ at day 7 and $96-100 \%$ at day 10 . The protection rates of melanin-containing feedstuffs varied widely depending on the type of feedstuff. In general, while the F3 feedstuff was not able to protect shrimp from WSSV attack, F1 and F2 had protection rates of 57\% and 64\% at day 7 and $42 \%$ and $62 \%$ at day 10 , respectively (Fig. 2b). 
A

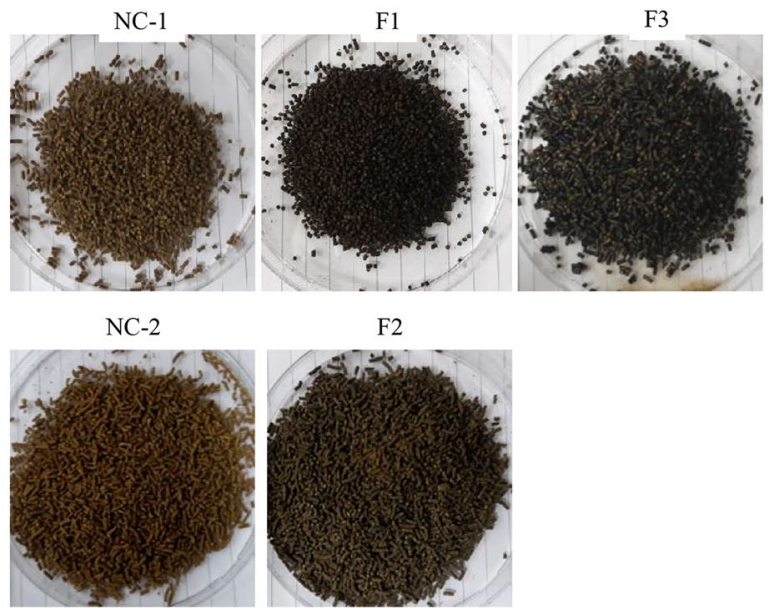

B

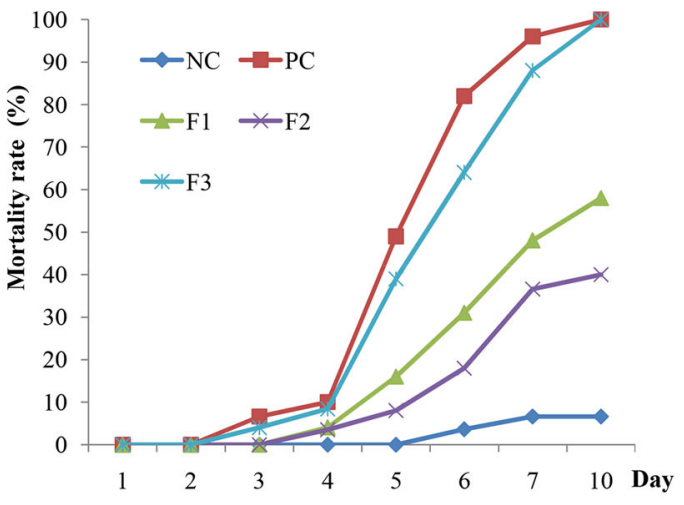

Fig. 2 Protection rates of different feed stuffs on WSSV-infected shrimps. a Appearances of commercial feed (NC1); commercial feed coated with melanin at ratio of $1 / 200(\mathrm{w} / \mathrm{w})$ and with the presence of cod oil as binding agent $(\mathrm{F} 1)$, modified commercial feed (mixed with 3\% starch solution) (NC2), commercial feed well mixed with melanin at ratio of 1/200 (w/w) and with the presence of starch $3 \%$ as cohesive agent (F2), and commercial feed directly coated with squid ink liquid at ratio 1/1 (w/v); b the accumulative mortality rates of shrimps fed with various feed stuffs (NC1, NC2, F1, F2, F3) at different days post-WSSV infection

Melanin-containing feedstuffs reduced the transcription level of VP28

Transcription levels of VP28 in shrimp were analyzed at day 7 and day 10 after virus challenge. The results showed that at day 7, the transcription level of VP28 in shrimp of the positive control (PC) pool and F1 pool were 4.6- and 5.0-fold higher than that in shrimp of the F2 pool, respectively (Fig. 3a). More impressively, at day 10, VP28 levels in shrimp of PC and F1 pools were almost twice those at day 7, while levels in shrimp of the F2 pool at day 10 were only 1.4-fold higher than those at day 7 (Fig. 3b).

A
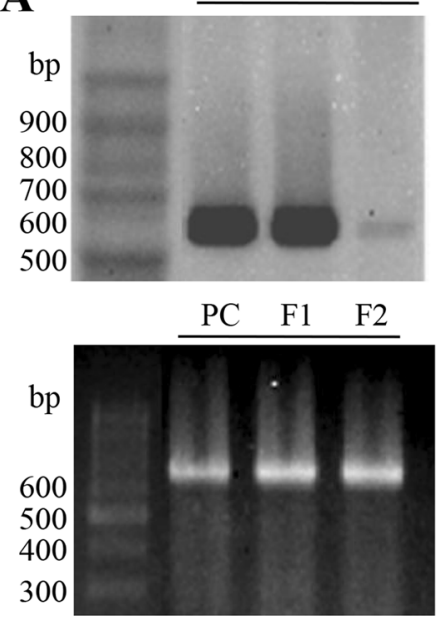

B

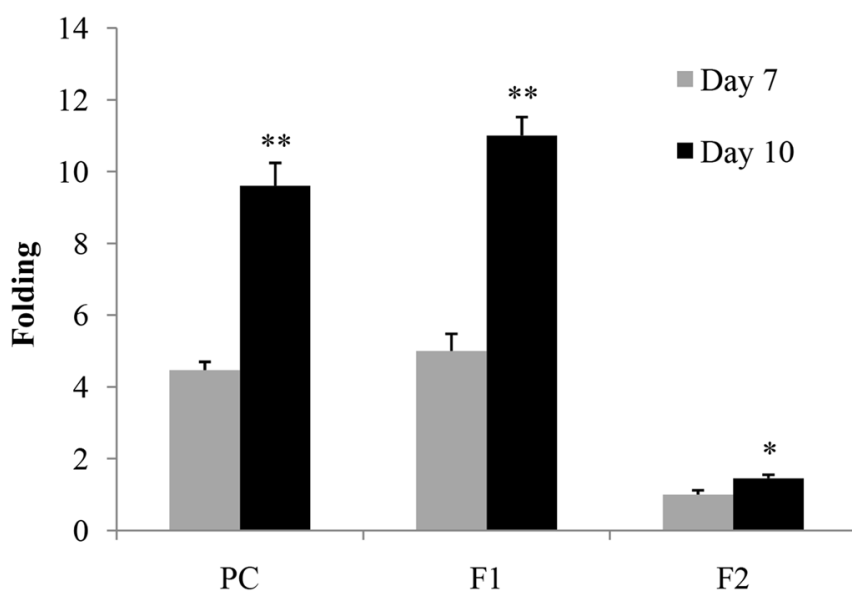

Fig. 3 Transcription levels of VP28 on WSSV-infected shrimps. a Transcription levels of VP28 on positive control (PC), F1-fed (F1) and F2-fed (F2) shrimps at day 7 post-WSSV infection. Beta-actin was used as internal control; b transcription levels of VP28 were quantitatively measured and presented in a graph. ${ }^{*}, * *$ Significant differences $(p<0.05$, and 0.01 , respectively) by the Student's $t$ test 
Protection rates of melanin-containing feedstuffs depended on amount of melanin consumed by shrimp

The same amount of melanin was supplemented in F1, F2, and F3 feedstuffs. During the experimental period, shrimp in all tanks were fed the same amount of feedstuffs and challenged with WSSV at day 3; representative images of the shrimp are shown in Fig. 4. The morphological differences among these three groups of shrimp were easily observed even with the naked eye (Fig. $4 \mathrm{a}-\mathrm{c}$ ). Consumed melanin was present in the shrimp intestines. Although the same amount of melanin was supplemented in F1 and F2 feedstuffs and the same amount of feedstuffs were fed to shrimp, the melanin consumed melanin by the shrimp of the F2 pool was much higher than that by the shrimp of the $\mathrm{F} 1$ pool. To explain this, the amount of melanin that released from the melanin-containing feedstuffs (F1 and F2) into water was examined using a spectrophotometer at a wavelength of $415 \mathrm{~nm}$. The results demonstrated that while the melanin in the F2 feedstuff was strongly bound inside the feed beads, melanin in the F1 feedstuff was easily released into water. Particularly, at 1, 2, 3 and $4 \mathrm{~h}$ after watering, the melanin amounts of F2 released in water were only 1/3.6, 1/2.5, 1/2.1, and 1/2.1 of those of F1, respectively (Fig. 4d).

\section{Discussion}

In general, shrimp mainly rely on innate immunity for protection against pathogen attacks (Witteveldt et al. 2004; Rout et al. 2007; Sutthangkul et al. 2017). However, melanin biosynthesis and release are also primary mechanisms that shrimp use to encapsulate pathogens (Tassanakajon et al. 2013; Nguyen et al. 2014). Melanin is a product created from the reaction of the shrimp immune system to envelop and excrete the pathogen into the environment (Tassanakajon et al. 2013; Nguyen et al. 2014). So far, there is no information about the quantity of melanin that shrimp produce in normal conditions and in virus-infected conditions. Therefore, it is unknown whether shrimp can produce enough melanin to sufficiently eliminate pathogens. More importantly, although the effects of endogenous melanin in shrimp have been identified, those of supplemented melanin (in the diet, for example) have not been investigated. Therefore, we presumed that supplying extrinsic melanin by oral administration may help shrimp capture and remove WSSV, which enters the intestinal tract of the shrimp.

A

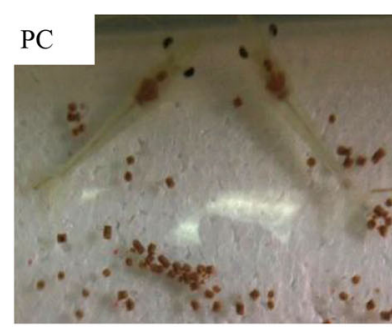

B

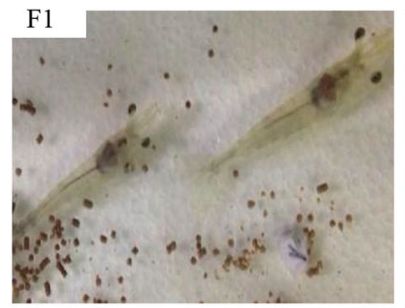

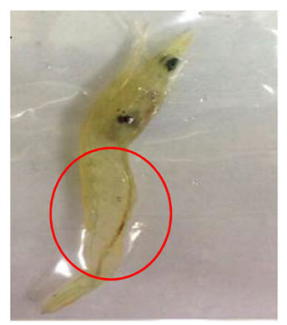

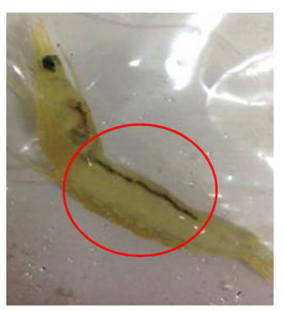

C
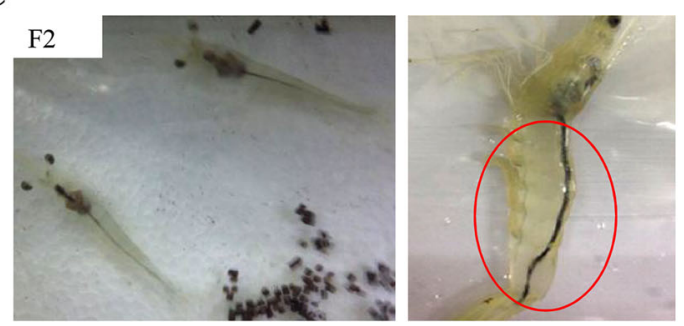

D

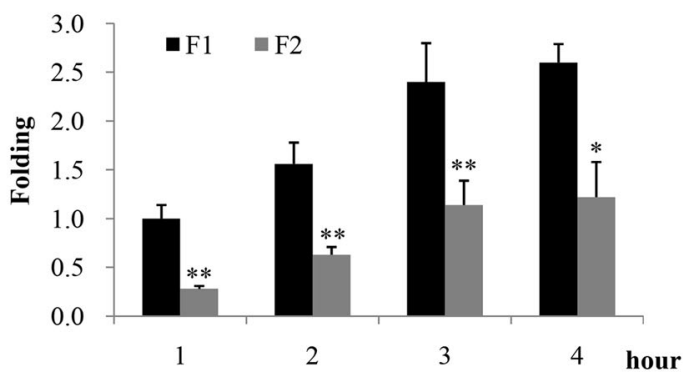

Fig. 4 Amount of melanin consumed by shrimps depended on the type of feed stuff. a-c The WSSV-infected shrimps fed with $\mathrm{NC} 1, \mathrm{~F} 1$ and F2 feed stuffs, respectively. The circle reds indicated the different amount of melanin in intestines of shrimps. d Melanin released from feed stuffs into environment. *,**Significant differences $(p<0.05$, and 0.01 , respectively) by the Student's $t$ test 
In this study, natural melanin extracted from squid ink-sac liquid, which is considered waste by seafoodprocessing companies, was supplemented as a feedstuff ingredient and fed to shrimp to investigate its ability to protect shrimp against WSSV attacks. Our results demonstrate that the formula used for preparing melanincontaining feedstuffs affects the protection capabilities of melanin supplementation in cultured shrimp. The melanin well-mixed feedstuff (F2) had a significantly higher protection rate compared with those of melanincoated feedstuffs (F1 and F3). The well-mixed form of F2 was able to capture melanin inside feed beads, whereas the coated formulas, F1 and F3, were not good at retaining melanin on their surfaces when dipped into water; thus, the amount of melanin consumed by shrimp fed F2 was much higher than that by shrimp fed F1 or F3. This result might consequently lead to differences in their protection abilities. Results of this study showed that the protection rate depended on the amount of melanin that shrimp had consumed; therefore, supplying a mixture of F2 and F3 feedstuffs to shrimp is unlikely to have a synergistic effect on the protection rate.

The results of this study indicate that the protection rate for shrimp fed the F2 feedstuff was around 60-65\%. This result was underwhelming, yet reasonable; melanin supplementation could only partially help shrimp capture and encapsulate viruses that entered via the digestive system, but it could not help eliminate viruses that infected shrimp by other modes of entry. Thus, the simultaneous use of other substances that can stimulate the activity of the immune system might be necessary. So far, many agents have been developed to protect shrimp against virus attacks, such as plant extracts and protein/DNA vaccines. However, while protection efficiencies of plant extracts are only around 40-50\% (Balasubramanian et al. 2006; Pholdaeng and Pongsamart 2010; Sudheer et al. 2011; Vaseeharan et al. 2006), recombinant protein/DNA-based vaccines, which might have protection rates as high as 70-75\%, are always treated with hesitancy associated with GMOs/GMFs (Witteveldt et al. 2004; Rout et al. 2007; Sutthangkul et al. 2017; Nguyen et al. 2014). Moreover, this study used natural melanin extracted from squid ink sacs, which is considered waste from seafood-processing factories. Therefore, utilizing this waste source to produce melanin would offer great benefits because of the low cost.

Based on the results of this study, we suggest that a protocol that simultaneously uses both melanin (as a supplement in feedstuffs) and plant extracts or vaccines be developed to create a synergistic effect on protecting shrimp against viral attacks. However, in farms, shrimp are always threatened with viral and bacterial infections. In the case of WSSV infection, it is very difficult to protect the shrimp pool when several individuals are infected. Therefore, farmers should periodically feed the shrimp melanin-containing feedstuff at appropriate intervals (depending on practical conditions) during the culturing period. Melanin-containing feedstuff is not expensive; thus, this protocol is likely to be cost-effective to farmers.

Funding This research is funded by Vietnam National Foundation for Science and Technology Development (NAFOSTED) under Grant number 106.02-2018.07.

\section{Compliance with ethical standards}

Conflict of interest All authors declare that they have no conflict of interest.

Open Access This article is distributed under the terms of the Creative Commons Attribution 4.0 International License (http:// creativecommons.org/licenses/by/4.0/), which permits unrestricted use, distribution, and reproduction in any medium, provided you give appropriate credit to the original author(s) and the source, provide a link to the Creative Commons license, and indicate if changes were made.

\section{References}

Balasubramanian G, Sudhakaran R, Syed MS et al (2006) Studies on the inactivation of white spot syndrome virus of shrimp by physichal and chemical treatments and seaweed extracts tested in marine and freshwater animal models. J Fish Dis 29:569-572

Balasubramanian G, Sarathi M, Venkatesan C, Thomas J, Sahul-Hameed AS (2008) Oral administration of antiviral plant extract of Cynodon dactylon on a large scale production against white spot syndrome virus (WSSV) in Penaeus monodon. Aquaculture 279:2-5

Brenner M, Hearing VJ (2008) The protective role of melanin against UV damage in human skin. Photochem Photobiol 84(3):539-549 
Charoensapsri W, Amparyup P, Suriyachan C, Tassanakajon A (2014) Melanization reaction products of shrimp display antimicrobial properties against their major bacterial and fungal pathogens. Dev Comp Immunol 47:150-159

Cuong AM, Le Na NT, Thang PN, Diep TN, Thuy LB, Thanh NL, Thang ND (2018) Melanin-embedded materials effectively remove hexavalent chromium (CrVI) from aqueous solution. Environ Health Prev Med 23(1):9

Garcia Borron JC, Malek AZ, Jimenez CC (2014) MC1R, the cAMP pathway, and the response to solar UV: extending the horizon beyond pigmentation. Pigment Cell Melanoma Res 27:699-720

Gunalan B, Soundarapandian P, Anand T, Kotiya AS, Simon NT (2014) Disease occurrence in Litopenaeus vannamei shrimp culture systems in different geographical regions of India. Int J Aquac 4:24-28. https://doi.org/10.5376/ija.2014.04.0004

Guzman AG, Sanchez MJG, Campa CAI, Gonzalez AL, Ascencio F (2009) Penaeid shrimp immune system. Thai J Vet Med 39:205-215

Harikrishnan R, Balasundaram C, Heo MS (2011) Impact of plant products on innate and adaptive immune system of cultured finfish and shellfish. Aquaculture 317:1-15

Hoffmann JA, Kafatos FC, Janeway CA, Ezekowitz RA (1999) Phylogenetic perspectives in innate immunity. Science 284:1313-1318

Jiravanichpaisal P, Bangyeekhun E, Soderhall K et al (2001) Experimental infection of white spot syndrome virus in freshwater crayfish Pacifastacus leniusculus. Dis Aquat Org 47:151-157

Jiravanichpaisal P, Soderhall K, Soderhall I (2006a) Characterization of white spot syndrome virus replication in in vitro-cultured haematopoietic stem cells of freshwater crayfish, Pacifastacus leniusculus. J Gen Virol 87:847-854

Jiravanichpaisal P, Lee BL, Soderhall K (2006b) Cell-mediated immunity in arthropods: hematopoiesis, coagulation, melanization and opsonization. Immunobiology 211:213-236

Lin ST, Chang YS, Wang HC, Tzeng HF, Chang ZF et al (2002) Ribonucleotide reductase of shrimp white spot syndrome virus (WSSV): expression and enzymatic activity in a baculovirus/insect cell system and WSSV-infected shrimp. Virology 304:282-290

Liu H, Soderhall K, Jiravanichpaisal P (2009) Antiviral immunity in crustaceans. Fish Shellfish Immunol 27:79-88

Nguyen TVA, Pham KC, Pham TTH et al (2014) Bacillus subtilis spores expressing the VP28 antigen: a potential oral treatment to protect Litopenaeus vannamei against white spot syndrome. FEMS Microbiol Lett 358:202-208

Pholdaeng K, Pongsamart S (2010) Studies on the immunomodulatory effect of polysaccharide gel extracted from Durio zibethinus in Penaeusmonodon shrimp against Vibrio harveyi and WSSV. Fish Shellfish Immunol 28:555-561

Rout N, Kumar S, Jaganmohan S, Murugan V (2007) DNA vaccines encoding viral envelope proteins confer protective immunity against WSSV in black tiger shrimp. Vaccine 25:2778-2786

Sudheer NS, Rosamma P, Bright Singh IS (2011) In vivo screening of mangrove plants for anti WSSV activity in Penaeus monodon, and evaluation of Ceriops tagal as a potential source of antiviral molecules. Aquaculture 311:36-41

Sutthangkul J, Amparyup P, Charoensapsri W et al (2015) Suppression of shrimp melanization during white spot syndrome virus infection. J Biol Chem 290:6470-6481

Sutthangkul J, Amparyup P, Eum JH et al (2017) Anti-melanization mechanism of the white spot syndrome viral protein, WSSV453, via interaction with shrimp proPO-activating enzyme, PmproPPAE2. J Gen Virol 98:769-778

Tang X, Wu J, Sivaraman J, Hew CL (2007) Crystal structures of major envelope proteins VP26 and VP28 from white spot syndrome virus shed light on their evolutionary relationship. J Virol 81:6709-6717

Tassanakajon A, Amparyup P, Somboonwiwat K, Supungul P (2010) Cationic antimicrobial peptides in penaeid shrimp. Mar Biotechnol (NY) 12:487-505

Tassanakajon A, Somboonwiwat K, Supungul P, Tang S (2013) Discovery of immune molecules and their crucial functions in shrimp immunity. Fish Shellfish Immunol 34:954-967

Van de Braak CB, Botterblom MH, Taverne N et al (2002) The roles of haemocytes and the lymphoid organ in the clearance of injected Vibrio bacteria in Penaeus monodon shrimp. Fish Shellfish Immunol 13:293-309

Vaseeharan B, Prem Anand T, Murugan T, Chen JC (2006) Shrimp vaccination trials with the VP292 protein of white spot syndrome virus. Lett Appl Microbiol 43:137-142

Vate NK, Benjakul S (2013) Antioxidative activity of melanin-free ink from splendid squid (Loligo formosana). Int Aquat Res 5:9. https://doi.org/10.1186/2008-6970-5-9

Wang YC, Chang PS, Chen HY (2007) Tissue expressions of nine genes important to immune defence of the Pacific white shrimp Litopenaeus vannamei. Fish Shellfish Immunol 23(6):1161-1177

Weidner D, Rosenberry B (1992) World shrimp farming. In: Proceedings of the special session on shrimp farming. World Aquaculture Society, Louisiana, pp 1-21

Witteveldt J, Vlak JM, van Hulten MC (2004) Protection of Penaeus monodon against white spot syndrome virus using a WSSV subunit vaccine. Fish Shellfish Immunol 16:571-579

\section{Publisher's Note}

Springer Nature remains neutral with regard to jurisdictional claims in published maps and institutional affiliations. 